\title{
Further geological and palaeoanthropological investigations at the Maludong hominin site, Yunnan Province, Southwest China
}

\author{
JI XuePing ${ }^{1 *}$, CURNOE Darren $^{2 *}$, BAO ZhenDe $^{3}$, HERRIES Andy I R $^{4}$, FINK David ${ }^{5}$, \\ ZHU YunSheng ${ }^{6}$, HELLSTROM John ${ }^{7}$, LUO Yun ${ }^{3} \&$ TACON Paul S C \\ ${ }^{1}$ Yunnan Institute of Cultural Relics and Archaeology, Kunming 650118, China; \\ ${ }^{2}$ School of Biological, Earth and Environmental Sciences, University of New South Wales, Sydney 2052, Australia; \\ ${ }^{3}$ Mengzi Institute of Cultural Relics, Mengzi 661100, China; \\ ${ }^{4}$ Archaeomagnetism Laboratory, Archaeology Program, School of Historical and European Studies, La Trobe University, Melbourne 3086, Australia; \\ ${ }^{5}$ Institute for Environmental Research, Australian Nuclear Science and Technology Organisation, Sydney 2001, Australia; \\ ${ }^{6}$ Honghe Prefectural Institute of Cultural Relics, Mengzi 661100, China; \\ ${ }^{7}$ School of Earth Sciences, University of Melbourne, Melbourne 3010, Australia; \\ ${ }^{8}$ Place, Evolution and Rock Art Heritage Unit, School of Humanities, Gold Coast Campus, Griffith University, Gold Coast 4222, Australia
}

Received March 28, 2013; accepted June 13, 2013; published online August 27, 2013

\begin{abstract}
Three-dimensional mapping and section work undertaken by us in 2008 have identified 11 stratigraphic units at Maludong site. AMS radiocarbon dating of charcoal established an accurate and internally consistent age profile for the sequence of $17.8 \pm 0.2 \mathrm{ka}$ to $13.2 \pm 0.1 \mathrm{ka}$. Archaeomagnetic analysis showed changes in externally derived pedogenically enhanced material consistent with a warming in climate between the cold period of Henrich Event 1 and the Bølling-Allerød interstadial. Human remains recovered during the 1989 excavation were derived from a deposit dating to this interstadial, or between $14.3 \pm 0.3 \mathrm{ka}$ and $13.5 \pm 0.1 \mathrm{ka}$. Anthropogenic features, including burnt rocks, baked sediment and thick charcoal and ash layers, were identified and examined through archaeomagnetic analysis. Two monkey fossils are described here, one of them being reassigned from Macaca robustus to $M$. aff. M. assamensis. They confirm the young age of the site and also show signs of anthropogenic alteration in the form of burning. Additional human cranial remains are reported for the first time and new data are provided for some specimens described previously. A range of new features is identified that strengthen the affinities of the Maludong remains to archaic humans. The presence of this globally unique mosaic of archaic and modern features raises important questions about human evolutionary history in East Asia during the Late Upper Pleistocene.
\end{abstract}

human evolution, Upper Pleistocene, Southwest China, archaic morphology, dating

Citation: Ji X P, Curnoe D, Bao Z D, et al. Further geological and palaeoanthropological investigations at the Maludong hominin site, Yunnan Province, Southwest China. Chin Sci Bull, 2013, 58: 4472-4485, doi: 10.1007/s11434-013-6026-5

Maludong (or Red Deer Cave) is a former quarry located on the edge of Huangjia mountain, Hongzhai Village, approximately $7 \mathrm{~km}$ southwest of Mengzi, Yunnan Province (Figure 1). The site was first investigated during August and September of 1989 by a team comprising members of the Palaeoanthropological Laboratory of the Yunnan Provincial Museum, Institute of Cultural Relics in Hani and Yi Au-

*Corresponding authors (email: jxpchina@foxmail.com; d.curnoe@unsw.edu.au) tonomous Prefecture of Honghe, and the Cultural Bureau of Mengzi County [1]. The results of this excavation were reported in a single article [1] and briefly summarised in English [2].

Excavation at Maludong recovered a large sample of macromammals, cultural materials and human remains. Eighteen mammal taxa were initially identified among the fossils representing modern taxa, but also including the extinct taxa Axis cf. yunnanensis and Macaca robustus. Faunal 


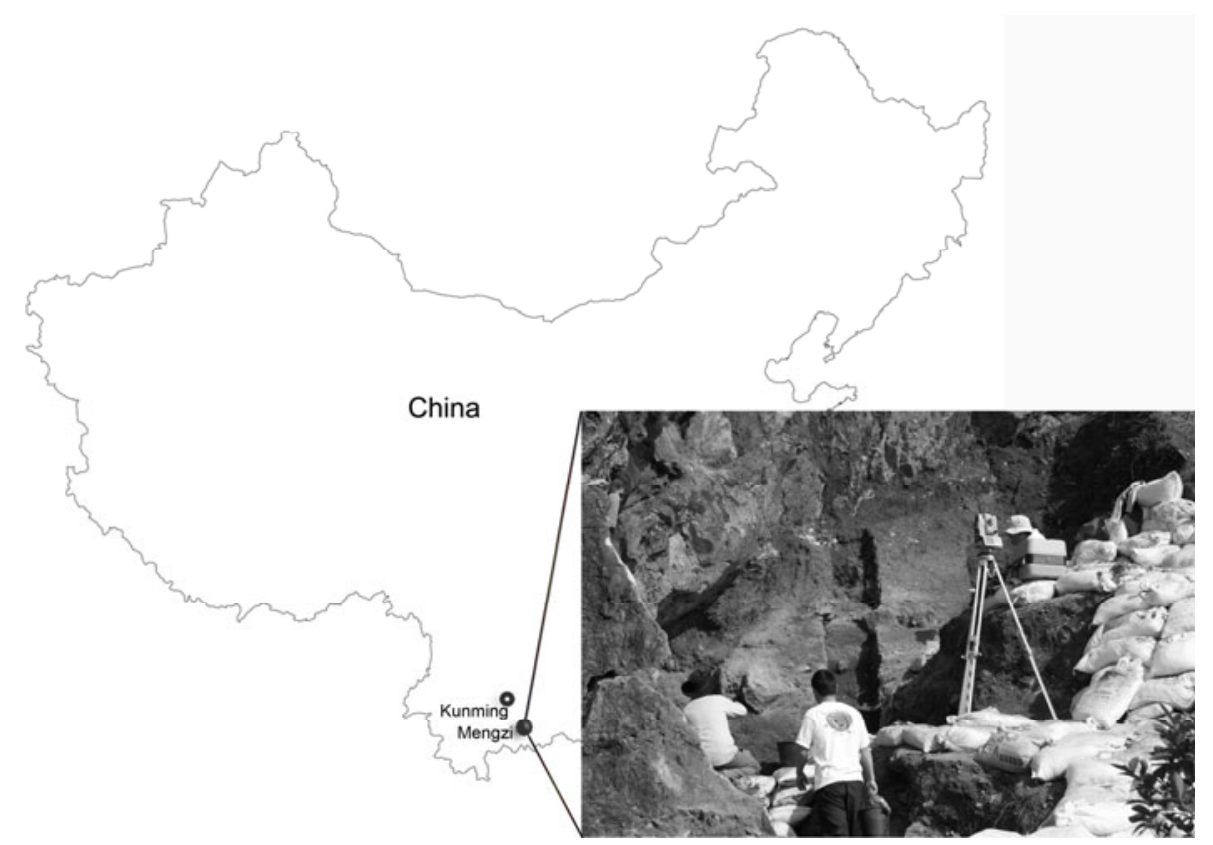

Figure 1 Maludong site: geographic location and image of sampling during section work in 2008.

comparisons with two other Yunnan localities (Lijiang and Tangzigou) led Zhang and co-workers to propose the main fossil and archaeological-bearing units at Maludong to be within the broad range of 30-6 ka [1]. The remains of up to five individuals were reportedly preserved in the human sample, including four fragmentary crania, an isolated mandible fragment with in situ dentition, and isolated postcranial elements including a proximal femur and distal ulna fragment [1]. The precise morphological affinities of the human remains were unclear at the time, with some archaic features noted, but all of them were assumed to belong to Homo sapiens [1].

The present article reports findings of a joint ChineseAustralian investigation at Maludong during 2008-2011 aiming to understand its stratigraphic sequence, determine the age of the deposits and to re-examine the archaeological and fossil remains recovered during 1989. Data from two non-human primate fossils are provided and the classification of one of them is reassessed. Descriptions, morphometric data and comparisons of some previously unknown human specimens are also provided, adding to recently published analyses of other Maludong remains [3].

\section{Methods}

\subsection{Stratigraphic section}

In December 2008, field research was undertaken at Maludong involving a team of Chinese and Australian researchers. The backfill was first removed from the site and used to fill sandbags. At the end of the 1989 field season, the remaining stratigraphic section had been covered with a large plastic sheet prior to reinterment of the backfill. This af- forded good protection of the section and it showed little evidence of disturbance when re-exposed in 2008. The site was comprehensively mapped by our team in 3-dimensions using a reflectorless laser total station. A geological section $(50 \mathrm{~cm} \times 50 \mathrm{~cm})$ was excavated vertically through the entire remaining section to record its stratigraphy. All finds of fossils and stone artefacts made during digging were also mapped. Samples were obtained from each spit for sediment characterisation and archaeomagnetic analysis. Additionally, sediment samples at $10 \mathrm{~cm}$ intervals were collected for archaeomagnetic analysis. Samples of charcoal and speleoethem were collected wherever possible through the section for AMS radiocarbon and uranium-series dating.

\subsection{Radiocarbon dating}

Fourteen samples were prepared for AMS radiocarbon assay and measured at the ANTARES-STAR Accelerator Mass Spectrometry Facility at the Australian Nuclear Science and Technology Organisation [4]. All samples were pre-treated and converted to graphite following the methods described by Hua et al. [5]. The external surfaces of charcoal pieces selected for assay were scraped with a cleaned scalpel to remove attached sediment and soil. The samples were then cut into smaller pieces to increase surface areas for more efficient chemical pre-treatment. Each sample was then treated with an acid-base-acid sequence as follows:

The $2 \mathrm{~mol} / \mathrm{L} \mathrm{HCl}$ at $60^{\circ} \mathrm{C}$ for $2 \mathrm{~h}$ to remove carbonate and any infiltrated fulvic acid contaminants, $0.5 \%-4 \% \mathrm{NaOH}$ at $60^{\circ} \mathrm{C}$ for $10 \mathrm{~h}$ to remove infiltrated fulvic and humic acid contaminants. This treatment was commenced with a very weak alkali solution of $0.5 \% \mathrm{NaOH}$ then with successively stronger solutions until the solution was clear or until all 
humic acids are removed, and $2 \mathrm{~mol} / \mathrm{L} \mathrm{HCl}$ at room temperature for $4 \mathrm{~h}$ to remove any atmospheric $\mathrm{CO}_{2}$, which was absorbed by the samples during the alkali treatment.

The cleaned charcoal pieces were finally placed into an oven at $60^{\circ} \mathrm{C}$ for $2-3 \mathrm{~d}$ to dry and then taken for combustion using routine methods for conversion of charcoal to graphite [4]. A portion of each graphite sample was used to determine $\delta^{13} \mathrm{C}$ for mass fractionation correction from the graphitisation process. Measured AMS ${ }^{14} \mathrm{C} /{ }^{13} \mathrm{C}$ ratios were converted to conventional radiocarbon ages after background subtraction and $\delta^{13} \mathrm{C}$ fractional correction. All radiocarbon ages were converted to calibrated calendar ages BP (beforepresent, 1950) using the CALIB 6.02 calibration software and the IntCal09 data sets (Stuiver M, Reimer P J, Reimer R W. CALIB 6.0, 2005: http://radiocarbon.pa.qub.ac.uk/calib/).

\subsection{Uranium-series dating}

Uranium series analyses were conducted on two speleothem samples from Maludong (MLDGU-01 and MLDGU02) using the protocols of Cheng et al. [6] and Hellstrom [7,8]. Two samples were collected at Maludong: MLDGU-01 on the wall of the cave close to the contact of stratigraphic unit BRRS (see below) with the ceiling, and MLDGU-02, a crystalline calcite block taken from within the stratigraphic layer BASE (see below).

\subsection{Archaeomagnetics}

The theory and methods surrounding the use of magnetic measurements for reconstructing palaeoclimate and anthropogenic alteration of sediments are outlined in Herries [9], Herries and Fisher [10] and Walden et al. [11]. Bulk sediment samples were collected from each stratigraphic unit during section work in 2008. Samples were divided into sub-samples, air dried and sieved to remove any large non-magnetic particles (i.e. limestone clasts). The sieved bulk subsamples were then subjected to a range of mineral magnetic measurements.

Low temperature and room temperature dual frequency magnetic susceptibility measurements were undertaken on a Bartington MS2 system. Isothermal remanent magnetisation (IRM) acquisition and backfield curves, hysteresis loops and thermomagnetic curves were run on a Magnetic Measurements Variable field Translation Balance (MM-VFTB). Burnt rocks from combustion features identified during section sampling were also subjected to a palaeomagnetic analysis of their thermal history and maximum heating temperature [9-12]. Samples were subjected to a 16-point stepwise thermal demagnetisation using a Magnetic Measurements Thermal Demagnetiser and were measured on an AGICO JR6 spinner magnetometer.

\subsection{Palaeoanthropology}

A conventional methodology was employed to study non- human primate and human remains. This included the checking of reconstructed remains for anatomical accuracy and possible post-burial distortion, assessment of palaeopathological markers and their possible altering effect on normal anatomy, and the identification and description of preserved anatomical elements and morphological attributes (qualitative character states). Bones and teeth were measured using digital vernier and spreading callipers (chords) and an osteometric tape (arcs) employing standard landmarks and measurements as described by Howells [13], Martin [14] and Wood [15]. Comparative data were taken from various sources: non-human primates [16-20] and human remains [2,3,21-49]. All measurements of the Maludong remains, and the mandibles KNM-BK 67 and KNM-BK 8518 used in comparisons, were taken on the original specimens by $\mathrm{D}$. Curnoe. We use the grade term "archaic" to refer collectively to non-modern (i.e. non-H. sapiens) species, as is convention in palaeoanthropology, recognising it has no systematic value.

\section{Results}

\subsection{Stratigraphic sequence}

Maludong represents the remains of a partly mined cave fill. Zhang et al. [1] stated that the original cave mouth was blocked with rock and earth before mining operations took place. The mouth was $8.2 \mathrm{~m}$ wide, $9.5 \mathrm{~m}$ high, and the cavity over $3 \mathrm{~m}$ in depth. Mining removed the western wall of the cave as well as most of the roof. The present cave is now a semi-circular roofless cavity in the mined cliff-face.

Zhang et al. [1] interpreted the cave sediments as being divided into three stratigraphic units: (1) a 4.5-m-thick upper layer of red sandy clay with limestone boulders and containing a few animal fossils; (2) a 5.0-m-thick grey cultural stratum intercalated with cemented blocks and a thin layer of red clay, rich in human fossils, stone artefacts and worked antlers, as well as fossil animals and plants; and (3) a basal layer comprising limestone boulders or basal limestone.

The in situ section investigated during 2008 is located in about the middle of the deposit (north-south direction) and is only $\sim 3.7 \mathrm{~m}$ deep from the roof to the base of the original excavation. During our digging, deposits were found below the basal unit identified by Zhang et al. [1], with the cave floor some $0.5 \mathrm{~m}$ beneath their original base. Taking account of the north-south slope in the sequence and maximum depth in the northern part of the cave, the maximum depth of the Maludong sequence can be no more than around $5.5 \mathrm{~m}$. Thus, the sequence depth of Zhang et al. [1] cannot be reconciled with the data collected in 2008 including our detailed 3D mapping. We suggest the earlier work might have overestimated the depth of the deposit. Alternatively, there may have been lateral variation in the deposition and depth of the 3 units identified, whose stratigraphy is essentially compressed in the current witness section. This seems 
possible given the distinct erosional event that occurred between what were likely layers 1 and 2. Unfortunately, this and other possible discrepancies that occur with the descriptions of the stratigraphy, including the fact that layer 1 is described as "containing a few animal fossils", and yet in the witness section, this unit has the highest density of fossils for the entire sequence, can no longer be established.

Figure 2(a) shows the 11 distinct sedimentological layers identified in 2008. Figure 2(b) indicates the excavated units and finds plotted using a laser total station. Finally, Figure 2(c) shows stratigraphic aggregates, or units, containing fossils and archaeological materials. The following units comprise the Maludong sequence:

Layer BASE (11): a dark brown clay containing charcoal and burnt bone with the bone generally covered in hard calcified sediment. This deposit lies on the limestone floor of the cave and is actually below the limestone boulders identified as the base of the deposit during the 1989 excavation. Thus, this unit was not recognised by Zhang et al. [1].

LGAC (10): a clay layer with a rock bound combustion feature and containing animal fossils and stone tools recovered during sampling in 2008.

OROC (9): an organic rich layer also containing animal fossils.

LSN (8): sterile limestone gravel that caps these three basal deposits.

Together, units $10-8$ comprise the bottom or 3rd layer described by Zhang et al. [1].

The next three units identified in 2008-ALROC (7), GAS (6) and ORS (5)-contain numerous combustion features, fossilised animal remains and charcoal. These deposits represent the middle or 2nd layer of Zhang et al. [1], with most of the human fossils recovered from the top of this unit. Fossil MLDG 1704 (see below) was recovered from just beneath the large fallen boulder in the top of GAS (Figure 2(a) and (b)). Moreover, a human tooth was recovered from this layer during the 2008 sampling reinforcing the provenience of the human remains.
Layer DGCA (4) was most likely included in the middle or second layer by Zhang et al. [1] due to its grey ashy character. However, this layer is sterile apart from flecks of charcoal. It seems to be natural in origin and represents a fine-grained channel fill. The layer is capped by a series of limestone blocks [LSRS (3)] on top of which is built a combustion feature. This hearth lies in the base of layer RS (2), which grades up into a bone rich deposit BRRS (1). RS and BRRS are part of the upper or first layer identified by Zhang et al. [1].

\subsection{Radiocarbon dating}

Full details of radiocarbon ages and calibrated calendar ages for each charcoal sample are provided in Curnoe et al. [3]. Radiocarbon ages are given with one standard deviation $(1 \sigma)$ precisions ranging from \pm 0.3 to \pm 0.5 . All calendar age errors quoted in this paper are given as $2 \sigma$ errors. For ancillary information relating to sample pre-treatment, graphite AMS mass and $\delta^{13} \mathrm{C}$ values used to correct AMS radiocarbon data from Maludong, see Curnoe et al. [3]. Figure 2(d) presents radiocarbon ages from Mauldong as an age depth profile.

Calibrated radiocarbon ages show the entire sequence to span the interval $17830 \pm 240$ cal. a BP (OZM152) to $13290 \pm$ 125 cal. a BP (OZM870) (Figure 2(d)). All of the human remains were recovered from within a series of deposits dating from 14310 $\$ 340$ cal. a BP (OZM149; $292 \mathrm{~cm}$ depth) to $13590 \pm 160$ cal. a BP (OZM145; $166 \mathrm{~cm}$ depth), a period of about 720 years (Table 1). Human remains recovered in situ in 2008 and the MLDG 1704 calotte derive from a subsection of these deposits dated between $13990 \pm 165$ cal. a BP (OZM148; $235 \mathrm{~cm}$ ) and 13890 \pm 140 cal. a BP (OZM146; $200 \mathrm{~cm}$ ) (Figure 2(d)), being deposited in an episode spanning around 100 years.

\subsection{Uranium-series dating}

Table 1 presents uranium-series results and age calculations.

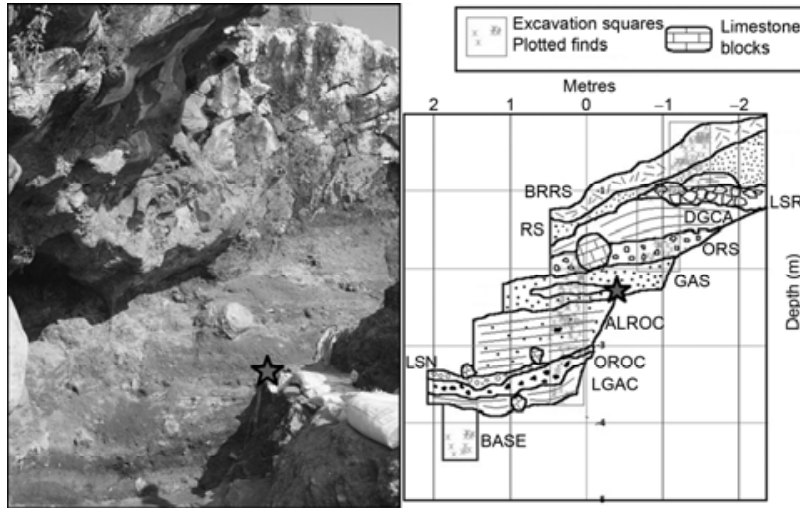

(a) (b)

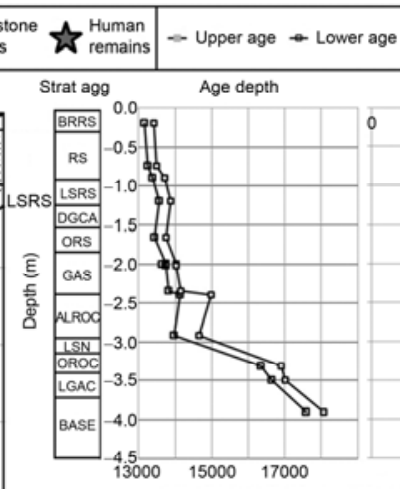

(d)
Magnetic susceptibility
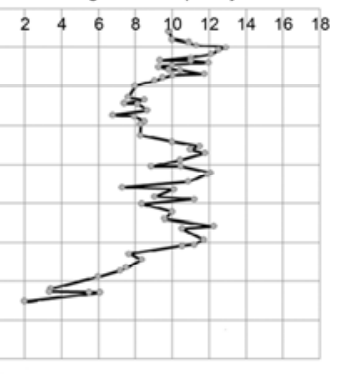

(e)

Figure 2 Maludong site: (a) stratigraphic sequence; (b) GIS plotted stratigraphy based on total station data and indicating sampling units and plotted finds; (c) stratigraphic aggregates; (d) upper and lower age limit of calibrated radiocarbon ages; and (e) magnetic susceptibility record $\left(\times 10^{-6} \mathrm{~m}^{3} \mathrm{~kg}^{-1}\right)$. 
Table 1 Uranium series results and age calculations ${ }^{\text {a) }}$

\begin{tabular}{clccccccc}
\hline Sample & Lab No. \& date & $\left.\mathrm{U}(\mathrm{ng} \mathrm{g})^{-1}\right)$ & {$\left[{ }^{230} \mathrm{Th}{ }^{238} \mathrm{U}\right]$} & {$\left[{ }^{234} \mathrm{U} /{ }^{238} \mathrm{U}\right]^{\mathrm{b})}$} & {$\left[{ }^{232} \mathrm{Th} /{ }^{238} \mathrm{U}\right]$} & {$\left[{ }^{230} \mathrm{Th} /{ }^{232} \mathrm{Th}\right]$} & Age $(\mathrm{ka})^{\mathrm{c})}$ & {$\left[{ }^{234} \mathrm{U} /{ }^{238} \mathrm{U}\right]^{\mathrm{d})}$} \\
\hline \multirow{2}{*}{ MLDGU-02 } & UMA03006 & & & & & & \\
& Nov 2009 & 104 & $1.047(18)$ & $1.020(05)$ & $0.0765(003)$ & 13.7 & $>630$ & - \\
\multirow{2}{*}{ MLDGU-01 } & $\begin{array}{l}\text { UMA03007 } \\
\text { Nov 2009 }\end{array}$ & 55 & $0.392(10)$ & $1.095(15)$ & $0.0193(001)$ & 20.4 & $45(3)$ & $1.108(17)$ \\
\hline
\end{tabular}

a) Numbers in brackets are 95\% uncertainties of the given least significant figures. b) Activity ratios determined after Hellstrom [8] using the decay constants of Cheng et al. [7]. Numbers in brackets are $95 \%$ uncertainties of the given least significant figures. c) Age in ka before present corrected for initial ${ }^{230} \mathrm{Th}$ using eq. (1) of Hellstrom [9] with $\left({ }^{230} \mathrm{Th} /{ }^{232} \mathrm{Th}\right)$ of $1.5 \pm 1.5$ for Maludong. d) Initial $\left({ }^{234} \mathrm{U} /{ }^{238} \mathrm{U}\right)$ calculated using corrected age.

Despite occurring on the wall of the cave at about the same level as the surface of the fossil bearing deposits, speleothem sample MLDGU-01 actually formed on the ceiling of the cave and has a much older date than the vertically equivalent sediments at $45 \pm 3 \mathrm{ka}$. This gives a minimum age for the formation of the cavern in which the sediments were deposited and highlights the need for caution when sampling speleothem from caves and the need for firmly establishing their stratigraphic context and association to fossil bearing sediments. Sample MLDGU-02, from the lower part of the sequence, provided an open-ended age $>630 \mathrm{ka}$ for the crystalline calcite. It likely samples the original vein fill of the fault on which the cave was formed. Similar crystalline calcite is seen filling vein cavities throughout the cliff-face into which the cave is dissolved.

\subsection{Archaeomagnetics}

Magnetic susceptibility $\left(\chi_{\mathrm{LF}} ; \times 10^{-6} \mathrm{~m}^{3} \mathrm{~kg}^{-1}\right)$ variation for the Maludong sediments is shown in Figure 2(e) (see also, Figure 3(a)-(c)). The Maludong sediments have very high magnetic susceptibility values ( $\chi_{\mathrm{LF}}$ up to $12.3 \times 10^{-6} \mathrm{~m}^{3} \mathrm{~kg}^{-1}$ and mean $9.6 \times 10^{-6} \mathrm{~m}^{3} \mathrm{~kg}^{-1}$ ) considering the fact that they were formed on a karst landscape. The samples all have a low coercivity with almost complete saturation of IRM curves by $100 \mathrm{mT}$ (Figure 3(a)) and are dominated by magnetite as shown by Curie temperatures of $\sim 575^{\circ} \mathrm{C}$. Extremely high frequency dependence of magnetic susceptibility $\left(\chi_{\mathrm{FD}} \%\right)$ values between $14 \%$ and $8 \%$ (mean $11.3 \%$ ) and a complete lack of a multi-domain peak at the Verwey transition in low temperature magnetic susceptibility curves indicates that this low coercivity is due to magnetic grains occurring that lie across the superparamagnetic (SP) to single domain (SD) grain size boundary. The samples instead have a flat magnetic susceptibility curve below $150^{\circ} \mathrm{C}$ and a linear increase back to room temperature, indicative of SP grains $[9,10,50]$. The thermomagnetic curves show little increase or decrease in magnetisation on cooling, which also confirms this mineralogy. These $\chi_{\mathrm{FD}} \%$ values are close to the maximum predicted value of natural samples for this grain size with $\chi_{\mathrm{FD}} \%$ values $>10 \%$, suggesting that such grain sizes make up as much as $75 \%$ of the assemblage [51].

The samples have undergone a high degree of ferromag- netic enhancement before they were deposited in the cave, which is due to high degrees of pedogenic alteration of welldrained soils in a warm and wet environment. The mineralogy of the bulk samples is extremely similar up through the section at Maludong, although, ferromagnetic enhancement is reduced in the basal layers (BASE, LGAC, ORC). Archaeomagnetic analysis reinforces the radiocarbon chronology of the site and shows changes in externally derived pedogenically enhanced material that is consistent with a warming in climate between the cooler Henrich 1 Event and the warmer Bølling-Allerød interstadial. The human remains and the bulk of the anthropogenic evidence for occupation occurs in the high magnetic susceptibility layers that suggest deposition in the Bølling-Allerød interstadial.

Palaeomagnetic analyses of burnt rocks [9,12] underlying the oldest combustion feature in LGAC suggest quite low temperatures between 250 and $350^{\circ} \mathrm{C}$ (Figure 3(d)). However, it has been shown that the temperature reached drops off quite rapidly with depth below a campfire [10]. This is important as it means that the underlying deposits are not significantly altered by secondary heating from later fireplaces [10]. Palaeomagentic results thus indicate that the rocks were heated and confirm the identification of anthropogenic combustion feature in LGAC, ALROC and RS. Baked clay deposits also have a higher magnetisation and lack a lower temperature phase transition that is seen in weaker unbaked clay (Figure 3(c)). These baked sediments also fit the magnetic character of burnt sediments as defined by Herries [9] and Herries and Fisher [10] in having higher $\chi_{\mathrm{LF}}$ and lower or similar $\chi_{\mathrm{FD}} \%$ values than unburnt sediments.

\subsection{Palaeoanthropology: non-human primate remains}

Two specimens identified as belonging to Macaca robustus [1] were recovered at Maludong during the 1989 excavations. The MLDG 1682 mandible fragment consists of the right body from just anterior to $\mathrm{M}_{1}$ to part of the anterior part (including take-off) of the ramus. The crown of $M_{1}$ is missing (roots in-tact), while the crowns of $\mathrm{M}_{2}-\mathrm{M}_{3}$ are well preserved. Specimen MLDG 1754 is a left maxilla comprising alveolar process from canine alveolus to $\mathrm{M}^{3}$, including in situ $\mathrm{P}^{3}-\mathrm{M}^{3}$ dentition, the left palatine process and horizontal plate of palatine bone are well preserved from intermaxillary- 

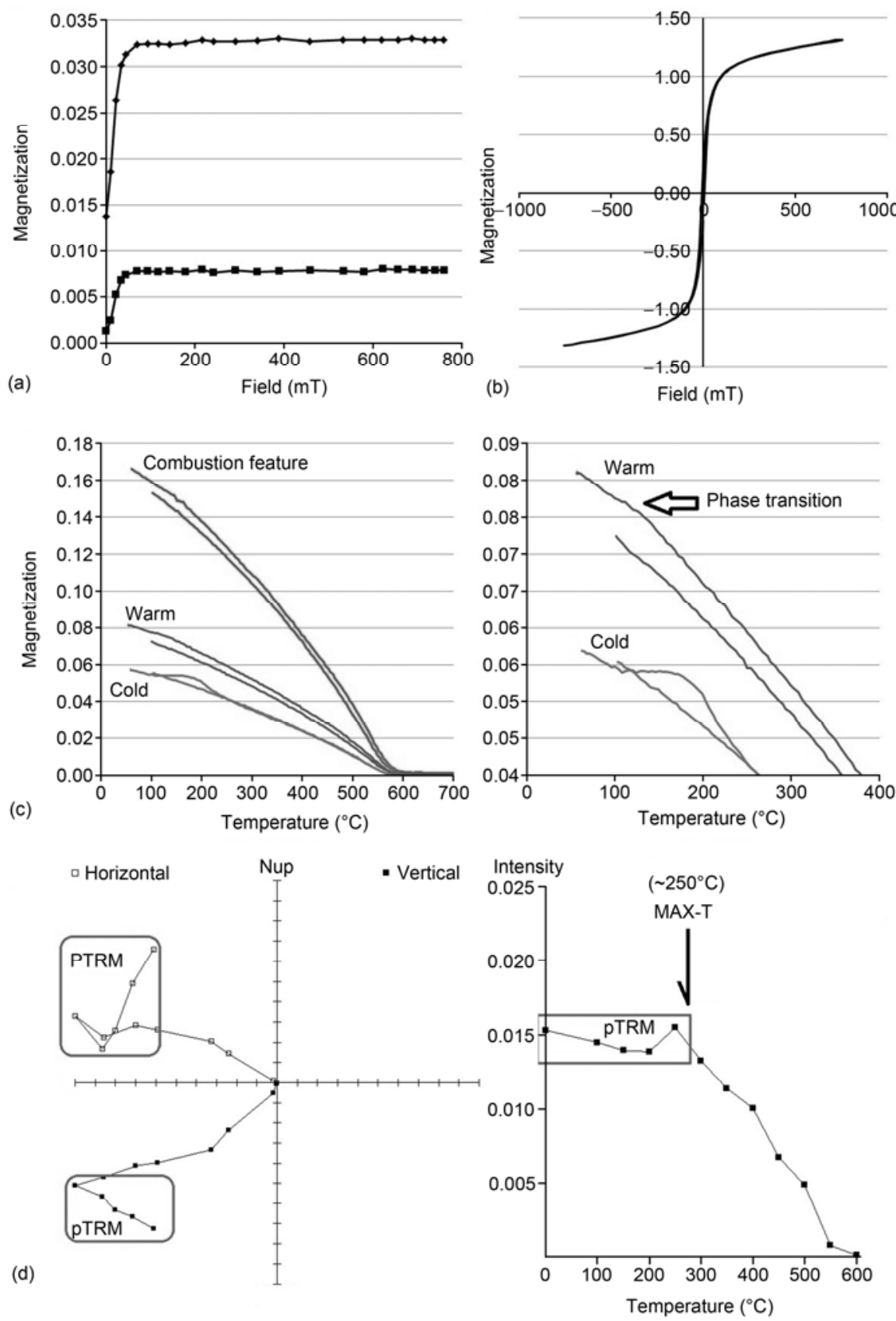

Figure 3 (a) IRM acquisition curves (warm and cold phases); (b) hysteresis loop; (c) thermomagnetic curves for low $X_{\mathrm{LF}}\left(\right.$ Cold period), medium $X_{\mathrm{LF}}$ (Warm period) and a baked clay combustion feature from Maludong; (d) palaeomagnetic analysis of burnt rock from beneath the oldest combustion feature in LGAC and indicating a maximum heating temperature (MAX-T) of $\sim 250^{\circ} \mathrm{C}$.

interpalatine sutures lateral, the maxillary tuberosity and left pyramidal process of palatine bone are intact, and the greater palatine foramen is apparent. This specimen shows extensive black staining indicating it has been burnt.

Measurements of the mandibular body (MLDG 1682) and mandibular and maxillary dental crowns (MLDG 1682 and MLDG 1754) are provided in Table 2. Table 3 compares maxillary $\mathrm{M}^{1}$ crown length (mesiodistal diameter) and width (buccolingual diameter) of MLDG 1754 with extant species of Macaca and extinct specimens/samples. Com- pared with modern taxa, the $\mathrm{M}^{1}$ crown of MLDG 1754 is moderate in size, plotting closest to male means for $M$. fuscata and M. assamensis.

The results of $z$-tests (Table 3) indicate that MLDG 1754 is most like the $M$. arctoides male mean for its mesiodistal diameter, and similar also to $M$. fuscata females and $M$. robustus. Its value is, however, within one standard deviation unit of the $M$. arctoides female, $M$. thibetana male and $M$. assamensis male means. Interestingly, $z$-tests highlight a statistically significant difference between MLDG 1754 and 
Table 2 Dental and mandibular body dimensions and shape indices (\%) for Maludong specimens assigned to Macaca $^{\text {a) }}(\mathrm{mm})$

\begin{tabular}{|c|c|c|}
\hline Measurement/Index & MLDG 1754 & MLDG 1682 \\
\hline Maxillary dentition & & - \\
\hline $\mathrm{P}^{3}$ & & - \\
\hline Mesiodistal diameter & 5.3 & - \\
\hline Buccolingual diameter & 6.5 & - \\
\hline $\mathrm{P}^{4}$ & & - \\
\hline Mesiodistal diameter & 5.4 & - \\
\hline Buccolingual diameter & 7.3 & - \\
\hline$M^{1}$ & & - \\
\hline Mesiodistal diameter & $\left(8.4^{\mathrm{a})}\right)$ & - \\
\hline Buccolingual diameter (mesial) & 7.5 & - \\
\hline$M^{2}$ & & - \\
\hline Mesiodistal diameter & 9.0 & - \\
\hline \multirow[t]{2}{*}{ Buccolingual diameter (mesial) } & 8.9 & - \\
\hline & & - \\
\hline Mandibular dentition & & - \\
\hline $\mathrm{M}_{2}$ & & - \\
\hline Mesiodistal diameter & - & - \\
\hline Buccolingual diameter (mesial) & - & 6.7 \\
\hline \multicolumn{3}{|l|}{$\mathrm{M}_{3}$} \\
\hline Mesiodistal diameter & - & 10.9 \\
\hline \multicolumn{3}{|l|}{ Mandibular body } \\
\hline Height at $\mathrm{M}_{1}$ & - & 22.0 \\
\hline Thickness at $\mathrm{M}_{1}$ & - & 8.1 \\
\hline Height at $\mathrm{M}_{2}$ & - & 19.9 \\
\hline Thickness at $\mathrm{M}_{2}$ & - & 9.0 \\
\hline Height at $M_{3}$ & - & 19.1 \\
\hline Thickness at $\mathrm{M}_{3}$ & - & 9.2 \\
\hline
\end{tabular}

a) Values in parenthesis are corrected for interstitial wear. the $M$. speciosa mean, as well as the $M$. mulatta mean; with M. sylvanus approaching significance.

For buccolingual diameter, the Maludong specimen is closest to the $M$. assamensis male mean, being one or greater than one standard deviation unit from the mean for all other samples. Finally, $z$-tests highlight a statistically significant difference between MLDG 1754 and the $M$. speciosa and $M$. mulatta means. These tests also highlight major distinctions with other taxa, the following means approaching significance in $z$-tests: $M$. arctoides males, $M$. assamensis females and $M$. thibetana males.

\subsection{Palaeoanthropology: Human remains}

A list of human remains curated and housed at the Honghe Prefectural Institute of Cultural Relics (Mengzi) was provided in Curnoe et al. [3]. The catalogue was compiled in 2008 and replaces the original designations given to the human cranial remains ("Skull 1", etc.) by Zhang et al. [1]. Most of the remains were recovered and identified during excavations in 1989. However, four large bags of fossils were collected during the 1989 fieldwork, but remained unsorted and their contents unidentified until they were washed, examined and identified in 2008. Through this process, an additional human hemi-mandible lacking dentition (MLDG 1679), a proximal ulna (MLDG 1710), maxillary fragment (MLDG 1713), a possible femoral head fragment (MLDG 1717) and several small cranial vault fragments were recovered from the unsorted material. Finally, an isolated partial $\mathrm{I}^{2}$ (MLDG 1751) was found in situ during our 2008 geological sampling work. Postcranial remains will be described and compared elsewhere.

(i) Mandibles. Specimens MLDG 1679 and MLDG 1706 have been described and compared elsewhere in detail [3]. Here, new data are provided for them in the form of symphysis and body measurements and shape index values (Table 4). In Table 5, dimensions and shape index values for MLDG

Table 3 Comparison of $\mathrm{M}^{1}$ crown diameters in MLDG $1754^{\mathrm{a})}(\mathrm{mm})$

\begin{tabular}{|c|c|c|c|c|c|c|c|c|c|c|}
\hline \multirow{2}{*}{ Species } & \multicolumn{5}{|c|}{ Mesiodistal } & \multicolumn{5}{|c|}{ Buccolingual } \\
\hline & $n$ & $\bar{x}$ & $s$ & $z$ & $p$ & $n$ & $\bar{x}$ & $s$ & $z$ & $p$ \\
\hline MLDG 1754 & & 8.4 & & & & & 7.5 & & & \\
\hline Macaca arctoides males & 12 & 8.3 & 0.5 & 0.19 & 0.42 & 12 & 8.3 & 0.5 & -1.54 & 0.07 \\
\hline Macaca arctoides females & 5 & 8.0 & 0.4 & 0.91 & 0.20 & 5 & 8.0 & 0.4 & -1.14 & 0.15 \\
\hline Macaca assamensis males & 12 & 7.9 & 0.5 & 0.96 & 0.17 & 12 & 7.4 & 0.6 & 0.16 & 0.43 \\
\hline Macaca assamensis females & 11 & 7.5 & 0.6 & 1.44 & 0.09 & 11 & 6.8 & 0.4 & 1.68 & 0.06 \\
\hline Macaca thibetana females & 3 & 8.5 & 0.2 & - & - & 3 & 8.3 & 0.2 & - & - \\
\hline Macaca speciosa mixed & 30 & 6.8 & 0.4 & 4.20 & 0.0001 & 24 & 6.1 & 0.3 & 5.43 & $<0.0001$ \\
\hline Macaca mulatta mixed & 12 & 7.2 & 0.2 & 7.21 & $<0.0001$ & 10 & 6.5 & 0.1 & 8.24 & $<0.0001$ \\
\hline Macaca sylvanus mixed & 35 & 7.8 & 0.4 & 1.48 & 0.07 & 35 & 7.1 & 0.4 & 0.99 & 0.16 \\
\hline Macaca fuscata males & 13 & 8.0 & 0.4 & 0.96 & 0.17 & 12 & 7.5 & 0.3 & - & - \\
\hline Macaca fuscata females & 18 & 7.69 & 0.3 & -0.29 & 0.38 & 19 & 7.1 & 0.3 & 1.06 & 0.15 \\
\hline Macaca robustus? Mixed & 5 & 8.7 & 0.8 & -0.41 & 0.35 & 5 & 8.5 & 0.9 & -1.10 & 0.16 \\
\hline
\end{tabular}

a) Scores in bold are approaching significance $(p=0.10-0.05)$ or statistically significant $(p<0.05)$. 
Table 4 Maludong mandibular body dimensions and shape indices (\%) $\left(\mathrm{mm}, \mathrm{mm}^{2}\right)$

\begin{tabular}{|c|c|c|}
\hline Measurement/Area/Index & MLDG 1679 & MLDG 1706 \\
\hline Height at symphysis & - & 27.7 \\
\hline Maximum thickness at symphysis & - & 12.5 \\
\hline Symphysis area & - & 345.14 \\
\hline Shape index at symphysis & - & 45.0 \\
\hline Body height at mental foramen & - & 26.9 \\
\hline Body width at mental foramen & - & 13.3 \\
\hline Body area at mental foramen & - & 358.17 \\
\hline Shape index at mental foramen & - & 49.5 \\
\hline Body height at $\mathrm{P}_{3}$ & - & 28.1 \\
\hline Body width at $\mathrm{P}_{3}$ & - & 13.0 \\
\hline Body area at $\mathrm{P}_{3}$ & - & 363.79 \\
\hline Shape index at $\mathrm{P}_{3}$ & - & 46.2 \\
\hline Body height at $\mathrm{P}_{3}-\mathrm{P}_{4}$ & - & 25.8 \\
\hline Body width at $\mathrm{P}_{3}-\mathrm{P}_{4}$ & - & 13.1 \\
\hline Body area at $\mathrm{P}_{3}-\mathrm{P}_{4}$ & - & 336.81 \\
\hline Shape index at $\mathrm{P}_{3}-\mathrm{P}_{4}$ & - & 50.8 \\
\hline Body height at $\mathrm{P}_{4}$ & - & 24.9 \\
\hline Body width at $\mathrm{P}_{4}$ & - & 12.8 \\
\hline Body area at $\mathrm{P}_{4}$ & - & 320.46 \\
\hline Shape index at $\mathrm{P}_{4}$ & - & 51.7 \\
\hline Body height at $\mathrm{P}_{4}-\mathrm{M}_{1}$ & - & 26.7 \\
\hline Body width at $\mathrm{P}_{4}-\mathrm{M}_{1}$ & - & 13.2 \\
\hline Body area at $\mathrm{P}_{4}-\mathrm{M}_{1}$ & - & 352.58 \\
\hline Shape index at $\mathrm{P}_{4}-\mathrm{M}_{1}$ & - & 49.6 \\
\hline Body height at $\mathrm{M}_{1}$ & - & 26.6 \\
\hline Body width at $\mathrm{M}_{1}$ & - & 13.2 \\
\hline Body area at $\mathrm{M}_{1}$ & - & 350.45 \\
\hline Shape index at $\mathrm{M}_{1}$ & - & 49.4 \\
\hline Body height at $\mathrm{M}_{1}-\mathrm{M}_{2}$ & - & 23.4 \\
\hline Body width at $\mathrm{M}_{1}-\mathrm{M}_{2}$ & - & 13.2 \\
\hline Body area at $\mathrm{M}_{1}-\mathrm{M}_{2}$ & - & 308.85 \\
\hline Shape index at $\mathrm{M}_{1}-\mathrm{M}_{2}$ & - & 56.4 \\
\hline Body height at $\mathrm{M}_{2}$ & 24.1 & 23.8 \\
\hline Body width at $\mathrm{M}_{2}$ & 16.4 & 14.6 \\
\hline Body area at $\mathrm{M}_{2}$ & 394.42 & 346.00 \\
\hline Shape index at $\mathrm{M}_{2}$ & 68.2 & 61.2 \\
\hline Body height at $\mathrm{M}_{2}-\mathrm{M}_{3}$ & - & 24.8 \\
\hline Body width at $\mathrm{M}_{2}-\mathrm{M}_{3}$ & - & 15.2 \\
\hline Body area at $\mathrm{M}_{2}-\mathrm{M}_{3}$ & - & 377.51 \\
\hline Shape index at $\mathrm{M}_{2}-\mathrm{M}_{3}$ & - & 61.3 \\
\hline Body height at $\mathrm{M}_{3}$ & 25.4 & 24.5 \\
\hline Body width at $\mathrm{M}_{3}$ & 19.3 & 14.7 \\
\hline Body area at $\mathrm{M}_{3}$ & 490.74 & 360.25 \\
\hline Shape index at $\mathrm{M}_{3}$ & 75.8 & 60.1 \\
\hline
\end{tabular}

1706 are compared with various Pleistocene human samples for the first time.

The symphysis of MLDG 1706 is moderate in height $(27.7 \mathrm{~mm})$, its value sitting well within the range of Pleistocene $H$. sapiens and $H$. neanderthalensis. Of the samples shown in Table 5, its value is closest to the mean for Middle Palaeolithic $H$. sapiens from West Asia and South Africa (mean $26.4 \mathrm{~mm}$ ), and furthest from East Asian Upper Palaeolithic $H$. sapiens with their tall symphyses. Symphysis thickness in MLDG $1706(12.5 \mathrm{~mm})$ is identical to $H$. neanderthalensis, and similar also to Middle Palaeolithic $H$. sapiens $(12.7 \mathrm{~mm})$ and European Upper Palaeolithic $H$. sapiens $(12.8 \mathrm{~mm})$. It is, however, distant from the mean for East Asian Upper Palaeolithic H. sapiens, the difference approaching statistical significance. The shape index value shows the Maludong mandibular symphysis to be moderately thin for its height (45.0\%). Its value is closest to the mean for Middle Palaeolithic H. sapiens (49.0\%), followed by European Upper Palaeolithic $H$. sapiens $(52.7 \%), H$. neanderthalensis (53.1\%) and finally East Asian Upper Palaeolithic H. sapiens (41.8\%).

Body height at the level of the mental foramen in MLDG $1706(26.9 \mathrm{~mm})$ is short, being closest to East Asian Upper Palaeolithic $H$. sapiens $(30.6 \mathrm{~mm})$. Its value is more distant from European Upper Palaeolithic $H$. sapiens (31.6 mm), $H$. neanderthalensis $(32.0 \mathrm{~mm})$ and Middle Palaeolithic $H$. sapiens $(35.0 \mathrm{~mm})$. Thickness at the level of the mental foramen is moderate $(13.3 \mathrm{~mm})$, being close to the means for Middle Palaeolithic H. sapiens $(14.0 \mathrm{~mm})$ and European Upper Palaeolithic H. sapiens $(12.6 \mathrm{~mm})$, but distant from the $H$. neanderthalensis $(15.6 \mathrm{~mm})$ and East Asian Upper Palaeolithic $H$. sapiens $(11.7 \mathrm{~mm})$. Shape index at the level of the mental foramen in MLDG 1706 (49.5\%) is significantly different to the mean for East Asian Upper Palaeolithic H. sapiens $(38.8 \%)$, and distant from the European Upper Palaeolithic H. sapiens mean (41.3\%). The Maludong specimen is similar to the mean for $H$. neanderthalensis (47.9\%), but contrasts with the Middle Palaeolithic H. sapiens mean $(40.4 \%)$.

Body height at the level of $\mathrm{M}_{1}-\mathrm{M}_{2}$ in MLDG 1706 (23.8 $\mathrm{mm}$ ) is moderately tall, being close to East Asian Upper Palaeolithic $H$. sapiens (23.4 mm), Middle Palaeolithic $H$. sapiens $(24.4 \mathrm{~mm})$ and European Upper Palaeolithic $H$. sapiens $(23.0 \mathrm{~mm})$, but more distant from $H$. neanderthalensis (20.9 mm). Thickness at the level of $\mathrm{M}_{1}-\mathrm{M}_{2}$ is identical to East Asian Upper Palaeolithic H. sapiens (14.6 mm), but distant from the means for Middle Palaeolithic H. sapiens (12.8 mm), H. neanderthalensis $(12.7 \mathrm{~mm})$, but approaching significance for European Upper Palaeolithic H. sapiens (11.9 mm). The $\mathrm{M}_{1}-\mathrm{M}_{2}$ body shape index value for MLDG $1706(61.2 \%)$ is very high (broad body for its width). Its value is almost identical to the $H$. neanderthalensis mean (62.0\%), relatively close to Middle Palaeolithic $H$. sapiens (53.6\%), but distant from the means for East Asian Upper Palaeolithic H. sapiens $(46.3 \%)$ and European Upper 
Table 5 Body dimensions and shape indices (\%) for MLDG 1706 compared $^{\text {a) }}(\mathrm{mm})$

\begin{tabular}{|c|c|c|c|c|c|}
\hline Measurement/Index & MLDG 1706 & $\begin{array}{c}\text { East Asian Upper } \\
\text { Palaeolithic } H \text {. sapiens }\end{array}$ & $\begin{array}{c}\text { European Upper } \\
\text { Palaeolithic H. sapiens }\end{array}$ & $\begin{array}{c}\text { Middle Palaeolithic } \\
\text { H. sapiens }\end{array}$ & $\begin{array}{c}\text { Homo } \\
\text { neanderthalensis }\end{array}$ \\
\hline Symphysis height & 27.7 & $32.4 \pm 2.1(6)$ & $24.3 \pm 3.8(20)$ & $26.4 \pm 5.2(5)$ & $23.6 \pm 3.3(16)$ \\
\hline$z$-score $(p)$ & & $-2.07(0.04)$ & $1.13(0.13)$ & $0.23(0.41)$ & $1.21(0.12)$ \\
\hline Symphysis thickness & 12.5 & $13.8 \pm 0.5(4)$ & $12.8 \pm 2.3(20)$ & $12.7 \pm 1.3(5)$ & $12.5 \pm 1.5(16)$ \\
\hline$z$-score $(p)$ & & $-2.33(0.05)$ & $-0.13(0.45)$ & $-0.14(0.44)$ & n.a. \\
\hline Symphysis shape index & 45.0 & $41.8 \pm 1.4(4)$ & $52.7 \pm 7.3(19)$ & $49.0 \pm 7.8(5)$ & $53.1 \pm 5.2(16)$ \\
\hline Height at mental foramen & 26.9 & $30.6 \pm 3.0(7)$ & $31.6 \pm 3.6(22)$ & $35.0 \pm 4.1(6)$ & $32.0 \pm 3.7(31)$ \\
\hline$z$-score $(p)$ & & $-1.15(0.14)$ & $-1.28(0.10)$ & $-1.83(0.06)$ & $-1.36(0.09)$ \\
\hline Thickness at mental foramen & 13.3 & $11.7 \pm 0.7(5)$ & $12.6 \pm 1.7(21)$ & $14.0 \pm 1.9(6)$ & $15.6 \pm 1.7(33)$ \\
\hline$z$-score $(p)$ & & $2.09(0.05)$ & $0.40(0.34)$ & $-0.34(0.37)$ & $-1.33(0.09)$ \\
\hline Shape index at mental foramen & 49.5 & $38.8 \pm 3.6(5)$ & $41.3 \pm 4.8(7)$ & $40.4(3)$ & 47.9 \\
\hline$z$-score $(p)$ & & $2.71(0.02)$ & $1.60(0.08)$ & - & - \\
\hline Height at $\mathrm{M}_{1}-\mathrm{M}_{2}$ & 23.8 & $23.4 \pm 3.8(3)$ & $23.0 \pm 3.3(11)$ & $24.4 \pm 4.4(5)$ & $20.9 \pm 4.1(19)$ \\
\hline$z$-score $(p)$ & & $0.09(0.46)$ & $0.23(0.41)$ & $-0.12(0.45)$ & $0.69(0.24)$ \\
\hline Thickness at $\mathrm{M}_{1}-\mathrm{M}_{2}$ & 14.6 & $14.6 \pm 4.8(6)$ & $11.9 \pm 1.8(11)$ & $12.8 \pm 2.0(5)$ & $12.7 \pm 1.4(18)$ \\
\hline$z$-score $(p)$ & & n.a. & $1.44(0.09)$ & $0.82(0.22)$ & $1.32(0.10)$ \\
\hline Shape index at $\mathrm{M}_{1}-\mathrm{M}_{2}$ & 61.2 & $46.3 \pm 8.9(3)$ & $52.8 \pm 8.8(11)$ & $53.6 \pm 10.9(5)$ & $62.0 \pm 7.9(18)$ \\
\hline$z$-score $(p)$ & & $1.45(0.14)$ & $0.91(0.19)$ & $0.64(0.27)$ & $-0.10(0.46)$ \\
\hline
\end{tabular}

a) $\bar{x} \pm \mathrm{s}(n) ; z$-scores in bold are approaching significance $(p=0.06-0.05)$ or are statistically significant $(p<0.05)$.

Palaeolithic H. sapiens (52.8\%).

(ii) Crania. The most complete cranium from Maludong (calotte MLDG 1704) has been described elsewhere in detail [3]. There is, however, another archaic feature not noted previously that requires mentioning: strong frontal dominance of the parieto-frontal chord and parieto-frontal arc indices: the value for both in MLDG 1704 being 92\%. In contrast, the mean for Pleistocene East Asian H. sapiens is significantly different to MLDG 1704 for the parieto-frontal chord index $106 \% \pm 4 \%(n 5, p=0.01)$ and approaching significance for arc index $105 \%(n 4)$. Additionally, the difference is approaching significance for the chord index value for Pleistocene European H. sapiens $104 \% \pm 7 \%(n 17)$ and Skhul-Qafzeh chord $107 \% \pm 7 \%(n 4)$, and for the H. erectus arc index mean of $84 \% \pm 4 \%$ ( $n 11)$. Its value for chord index is, however, closest to the $H$. erectus mean $(89 \% \pm 7 \%, n 11)$, although, also within one standard deviation of the mean for $H$. neanderthalensis $(98 \% \pm 8 \%, n 10)$ and $H$. heidelbergensis $(103 \% \pm 12 \%, n 4)$. For the arc index, it is most similar to the $H$. neanderthalensis mean $(96 \% \pm 10 \%, n 9)$, although, also within one standard deviation of the Pleistocene European $H$. sapiens $(99 \% \pm 7 \%, n 19)$ and $H$. heidelbergensis $(98 \% \pm$ $10 \%, n 5)$ means.

Specimen MLDG 1705 has not been described until now and comprises 15 burnt pieces of cranial vault bone supported in plaster (Figure 4). The specimen includes a frontal squama fragment (right side), just over half the right parietal, and about one-third of the left parietal. The sagittal suture is preserved for much of its anteroposterior course. Some denticulations of the lambdoid suture are intact (right side). Owing to incompleteness and the strong likelihood of shrinkage

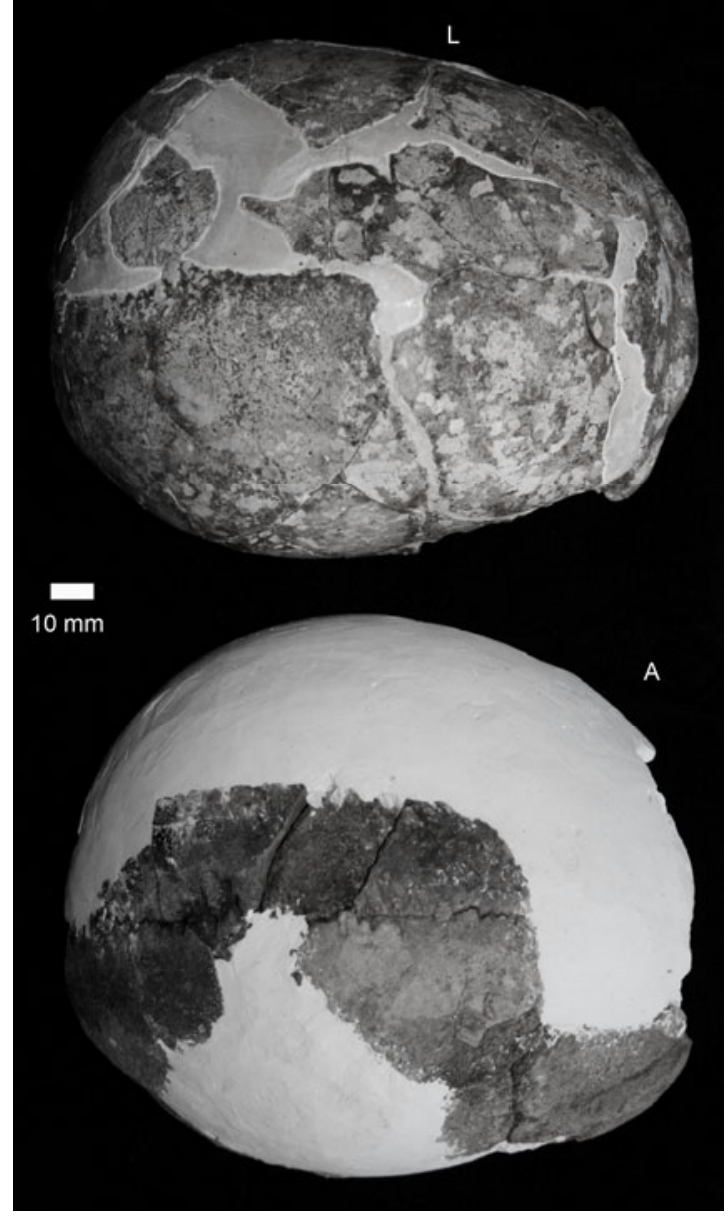

Figure 4 Maludong partial cranial vaults MLDG 1704 (above) and MLDG 1705 (below) (L: left side; A: anterior). 
Table 6 Maludong human dental crown dimensions and shape indices $(\%)\left(\mathrm{mm}, \mathrm{mm}^{2}\right)$

\begin{tabular}{|c|c|c|c|c|c|c|c|c|c|c|}
\hline & \multicolumn{5}{|c|}{$\mathrm{M}_{2}$} & \multicolumn{5}{|c|}{$\mathrm{M}_{3}$} \\
\hline & $\begin{array}{l}\text { Occlusal } \\
\text { wear }^{\mathrm{a}}\end{array}$ & MD & BL & Crown area & $\begin{array}{l}\text { Crown } \\
\text { shape } \\
\text { BL/MD }\end{array}$ & $\begin{array}{l}\text { Occlusal } \\
\text { Wear }^{\mathrm{a}}\end{array}$ & MD & $\mathrm{BL}$ & Crown area & $\begin{array}{c}\text { Crown } \\
\text { shape } \\
\text { BL/MD }\end{array}$ \\
\hline \multicolumn{11}{|c|}{ Mandibular crowns } \\
\hline MLDG 1679 & 4 & $\begin{array}{c}12.9 \\
\left(13.7^{\mathrm{b}}\right)\end{array}$ & 11.9 & $\left(162.89^{c}\right)$ & $\left(86.9^{c}\right)$ & 3 & $\begin{array}{c}10.9 \\
\left(12.2^{\mathrm{b}}\right)\end{array}$ & 11.6 & $\left(141.76^{c}\right)$ & $\left(95.1^{\mathrm{c}}\right)$ \\
\hline \multicolumn{11}{|c|}{ Maxillary crown } \\
\hline MLDG 1747 & - & - & - & - & - & 7 & $\begin{array}{c}9.0 \\
(9.7)\end{array}$ & 12.5 & (121.4) & (128.9) \\
\hline
\end{tabular}

a) Scored using system of Wood [16]; b) MD corrected for interstitial wear; c) employs corrected MD value.

associated with burning, the morphology of this specimen is difficult to reliably reconstruct and measurements are unlikely to be accurate. Vault thickness is minimally estimated to be $8.2 \mathrm{~mm}$ (taken at bregma) and $8.7 \mathrm{~mm}$ (taken at lambda).

(iii) Dentition. A number of teeth have been recovered from Maludong including in situ mandibular $\mathrm{M}_{2}$ and $\mathrm{M}_{3}$ (MLDG 1679, see [3]) and an isolated maxillary third molar (MLDG 1747, see [3]). In Table 6, we present previously unpublished estimates of wear and crown measurements (mesiodistal and crown areas) and shape index values for these teeth.

Figure 5(a) compares $\mathrm{M}_{2}$ and $\mathrm{M}_{3}$ buccolingual (BL) diameters for MLDG 1679 with a range of Pleistocene samples and fossils. There is considerable overlap of samples, with all Pleistocene modern human and $H$. neanderthalensis means sitting within one standard deviation of each other. The Maludong crown is large and most closely resembles mean values for the Skhul-Qafzeh sample and $H$. erectus, although, it clearly also sits within the range of Pleistocene European and East Asian $H$. sapiens. Its value for $\mathrm{M}_{2} \mathrm{BL}$ is approaching significance for East Asian early modern humans $(11.1 \pm 0.8 \mathrm{~mm} ; n 7)$ and is significantly different to the mean for Sima de los Huesos (H. heidelbergensis) (10.2 \pm $0.7 \mathrm{~mm} ; n 39, p=0.01)$. For $\mathrm{M}_{3} \mathrm{BL}$, the difference between MLDG 1679 and the mean for Sima de los Huesos $(9.8 \pm 0.7$ $\mathrm{mm}, n 38)$ is significant $(p=0.007)$.

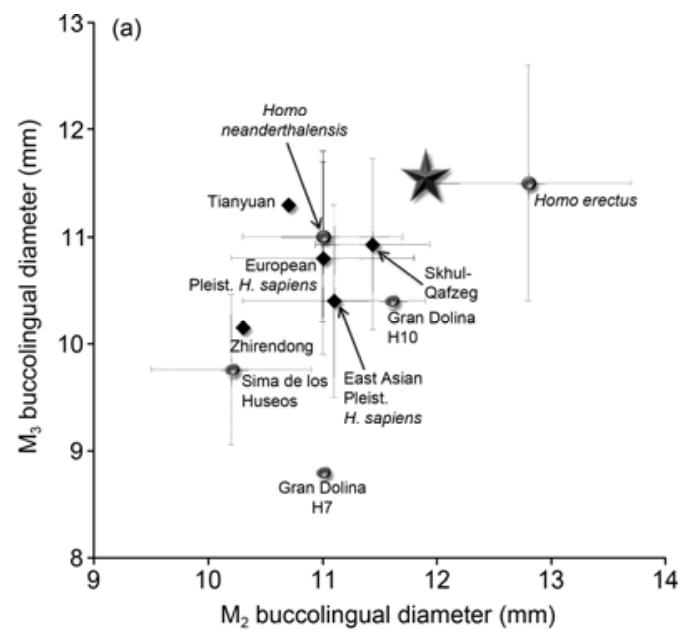

Figure 5(b) compares crown shape (BL/MD) index values for MLDG 1679 with Pleistocene archaic and modern humans. While there is considerable overlap of modern and some archaic sample ranges, the narrow crowned molars of MLDG 1679 are similar in shape to the Gran Dolina $(H$. antecessor) specimen $\mathrm{H} 7$, Sangiran 37 (H. erectus) and the $H$. neanderthalensis mean. The Pleistocene modern human from Chuandong also sits among archaic humans, but away from MLDG 1679, while the Huanglong human has broad molar crowns. Differences between MLDG 1679 and some sample means are statistically significant: $\mathrm{M}_{2}$ crown shapeAtapuerca Sima de los Huesos $(93.3 \% \pm 2.9 \% ; n 15, p=0.02)$, Skhul-Qafzeh $(103.4 \% \pm 4.9 \% ; n 8, p=0.007)$ and European Upper Palaeolithic H. sapiens $(n 18, p=0.01)$. Moreover, the difference between MLDG 1679 and the Zhoukoudian sample mean is approaching significance $(97.1 \% \pm 5.7 \% ; n 18)$. For $\mathrm{M}_{3}$ crown shape, the difference between MLDG 1679 and the Atapuerca Sima de los Huesos is also approaching significance $(87.9 \% \pm 4.3 \% ; n 16)$.

\section{Discussion}

\subsection{Stratigraphy, dating and archaeomagnetics}

The results of AMS radiocarbon dating of charcoal collected

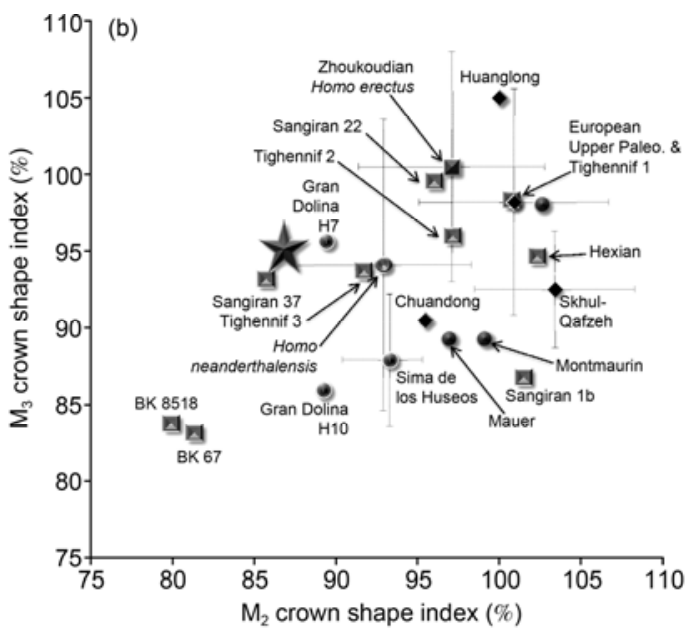

Figure 5 Mandibular $\mathrm{M}_{2}$ versus $\mathrm{M}_{3}$ crowns in MLDG 1679 (gray star) compared. (a) Buccolingual diameters; (b) crown shape index values (error bars=1 $\sigma$ ). 
from the Maludong sequence during 2008 provide unambiguous absolute ages for the stratigraphic units recognised by us. The magnetic susceptibility record corroborates the stratigraphically coherent and internally consistent radiocarbon-based chronology for the site, indicating that the dated charcoal was deposited at the same time as its enveloping sediments (Figure 2(d)). The much older age of the uranium series dates compared to the radiocarbon ages from charcoal in the adjacent sediments highlights the importance of knowing the context of speleothems that have formed on the walls or ceilings of caves that appear to be in close contact with the sediments.

The cavity at Maludong probably formed $>630 \mathrm{ka}$ and may have opened as recently as $45 \pm 3 \mathrm{ka}$. Sediment and clasts began to infill the cave around $17.8 \pm 0.2 \mathrm{ka}$, with deposition ending around 13.2 $\pm 0.1 \mathrm{ka}$. The sequence of deposits at Maludong comprises 11 distinct sedimentological layers, including a basal layer not previously recognised. The lower three units (BASE, LGAC and OROC) are all fossil bearing layers that lie within the range of around $17.8 \pm 0.2 \mathrm{ka}$ to $16.6 \pm 0.2 \mathrm{ka}$. Combustion features in LGAC indicate that humans were occupying the cave during the cooler period Henrich 1 period [52], dated around $16.8 \mathrm{ka}$, and not just during the later, warmer Bølling-Allerød interstadial, however, occupation was likely to have been more limited. These older deposits were sealed by a sterile limestone gravel deposit (Unit 8).

Above this, a major change in depositional rates occurs, as shown by the radiocarbon ages (Figure 2(d)). Units 7-5 (ALROC, GAS and ORS) contain numerous combustion features, fossilised animal remains and charcoal, included the human remains, and are dated to between around $14.3 \pm 0.3 \mathrm{ka}$ and $13.5 \pm 0.1 \mathrm{ka}$. The archaeomagnetic data and correlation of the radiocarbon dates to other dated palaeoclimatic sequences from China (e.g. Hulu Cave [53]) indicate these units were deposited during the warmer and wetter Bølling-Allerød interstadial.

Because GAS contained various human specimens (including MLDG 1704), numerous charcoal samples were collected, including samples from in situ combustion features, and radiocarbon dates produced to determine its age. These all indicate the layer containing MLDG 1704 to be between around $13.9 \pm 0.1 \mathrm{ka}$ and $13.8 \pm 0.1 \mathrm{ka}$, giving a very secure maximum age range for this fossil. These three layers have been sealed by DGCA (4), a sterile unit apart from small flecks of charcoal dated to around $13.7 \pm 0.1 \mathrm{ka}$. Sitting on top of DGCA is a unit containing a series of limestone blocks [LSRS (or unit 3)]. Finally, the upper two units (RS and BRRS) are also fossil bearing and appear to have been deposited following a major erosional event. The bone from this deposit is of a distinct chalky white character, while below LSRS the bone has been heavily calcified and is often enclosed in a layer of calcified sediment. The densely packed fossils from the top of this uppermost phase (unit BRRS) are extremely fragmented perhaps suggesting a dif- ferent taphonomic agent, or alternatively carnivore activity given the occurrence of fossils of such accumulating agents at the site (Canidae gen. et sp. indet, Felis sp., Viverra sp., Meles sp.) and notably, Ursus thibetanus (the Asian black bear) [1]. Taphonomic work will be undertaken in the future, but is complicated by the sourcing of the bulk of the material excavated in 1989. Radiocarbon dates show this upper phase to date between around $13.5 \pm 0.1 \mathrm{ka}$ and $13.2 \pm 0.1 \mathrm{ka}$.

Within the section, four distinct phases of anthropogenic activity (AA-1 to AA-4) can be distinguished based on plotted find density, geochronology and the presence of combustion features that were defined by their morphology during geological sampling and by archaeomagnetic analysis (Figure 2(c)-(d)). Three of the four phases encompass more than one stratigraphic aggregate and are separated from each other by archeologically sterile layers of roof collapse and alluvial deposit, or a short erosional hiatus (Figure 2(c)). As such, the site may not have been continuously occupied with only the anthropogenic phase 3 from which human remains have been definitively recovered definitively showing extensive evidence for cave use.

\subsection{Palaeoanthropology}

(i) Non-human primates. Macaque remains recovered from Maludong are difficult to classify definitively owing to their incompleteness. Dental measurements of the $\mathrm{M}^{1}$ from MLDG 1754 show strongest affinities to male means for the extant taxa M. assamensis and M. fuscata (Table 3). Macaca assamensis seems the most likely attribution for the specimen, in light of these similarities, the results of $z$-tests (Table 3), and the geographic location and age of Maludong. The species is today distributed from Nepal east through the Himalayas to southern China and north and central Southeast Asia [54]. It is thought to occupy higher altitude areas and to prefer evergreen forest areas and rugged or karst terrain [55]. The species has also been recovered from late Pleistocene deposits in Vietnam [56]. While the classification of the other Macaca specimen (MLDG 1682) is left open, it is probably best considered as belonging to the same species. Thus, identification of MLDG 1754 as most likely belonging to an extant macaque species confirms the young age of the site and also shows the faunal assemblage to contain only one extinct taxon (Axis yunnanensis). Finally, evidence of anthropogenic burning is likely to indicate that non-human primates were being exploited for food by the inhabitants of Maludong.

(ii) Human remains. When the archaic features described here are combined with those noted previously by us for the Maludong remains [3], the list is comprehensive (21 traits):

Vault: narrow frontal/low constriction index value, strong frontal dominance of parieto-frontal chord and parieto-frontal arc indices, wide interorbital part, well-developed post-toral shelf, vertically thick supraorbital (medial), thick vault bones, and endocast: short parietal chord. 
Mandible: Chin Rank 3, absence "inverted-T" form, anterior border of the body (beneath the symphysis) is rounded (inferior view), high shape index value at the level of the mental foramen, high shape index value at level of $\mathrm{M}_{1}-\mathrm{M}_{2}$, absence of mandibular foramen bridging (MLDG 1679 only), asymmetrical mandibular notch (MLDG 1679), retromolar space, mandibular notch meets the condyle medially (MLDG 1706 only), transverse tori thickened, externally symphysis undercut, and anterior symphyseal angle very low.

Dentition: Molar taurodontism, absolutely broad (BL) molar crowns, and relatively narrow M2 crown (BL/MD shape index).

The presence of some putative archaic features in the earliest modern humans across Eurasia has been noted previously including in some Chinese fossils [2,57-60]. Yet, among all of these remains, the Maludong humans stand out for exhibiting a much larger number of archaic features and spanning multiple regions of the skeleton [3]. Moreover, many of the characters seen at Maludong are in low frequency or absent among Pleistocene and recent modern humans globally. This situation is all the more striking given their young geological age as shown above.

It seems unlikely that the Maludong remains simply represent very robust members of a late Pleistocene modern human population, perhaps people who acquired their archaic features through evolutionary reversal owing to isolation and random genetic drift. Other populations of similar age that are clearly anatomically modern (i.e. lacking archaic traits) have been recovered from various localities in the surrounding region (e.g. [2,3,27,36-38,58,59,61]). Moreover, genetic research shows that far from being isolated, southwest China today contains high diversity and is likely to have been a "genetic reservoir" for modern humans following their appearance in East Asia [62,63].

Another possibility is that the mosaic of features in Maludong could result from interbreeding between modern humans and an archaic population such as Neandertals, the Denisovans $[64,65]$ or an unknown archaic group. This hypothesis cannot be tested at present owing to an absence of archaic East Asian fossils dated $<100 \mathrm{ka}$, and our inability so far to extract authentic DNA from the Maludong remains [3]. While genomic sequence comparisons suggest the Denisovans may have inhabited Southeast Asia during a time when it was also occupied by modern humans [64,65], the young age of Maludong post-dates this by perhaps $>20 \mathrm{ka}$. This is also seemingly at odds with a scenario involving hybridisation.

The most plausible scenario at present seems to be that the Maludong fossils along with those from Longlin cave [3] might represent a late surviving archaic population. Their morphology implies the existence of a "gap" between the anatomical features of the Maludong-Longlin specimens and the modern humans occupying the surrounding region and points towards a genetic and historical break. If they were taken to simply be "usual" members of $H$. sapiens, then the existence of such a peculiar morphological mosaic in sympatry with other people whose morphology is clearly anatomically modern, and seemingly for many thousands of years, would need to be explained. We refrain from classifying the Maludong remains at this time pending further detailed work on them as well as additional research on the Longlin Cave partial skeleton [3].

\section{Conclusions}

The establishment of a precise chronology at Maludong will allow questions about the palaeontology and archaeology of the late Pleistocene of Southwest China to be addressed with greater certainty. For example, future research could address questions surrounding the palaeoecology of the region including the late persistence and extinction of megafauna species. Maludong also adds significantly to our understanding of recent human evolution in East Asia. Human remains from the locality show that during the PleistoceneHolocene transition the late hunter-gatherers of southwest China were characterised by remarkable levels of morphological variability, with a mosaic of features unseen until now anywhere in the world. This indicates that human evolution during this time was far more complicated than has hitherto been understood, with multiple populations inhabiting the region at a time when the profound economic and ecological changes accompanying the Epipalaeolithic were already underway [66]. Further work will be required to classify the Maludong remains with certainty and to establish precisely what their relationships were to other humans inhabiting this and other regions at the end of the Pleistocene.

The authors thank the Australian Research Council (DP0877603), the Yunnan Institute of Cultural Relics and Archaeology, the University of New South Wales and Griffith University for funding this research. We are very grateful to Ruliang Pan, Yang Decong (Yunnan Institute for Cultural Relics and Archaeology), He Guangshu (Vice Director, Education, Science, Culture and Health Committee of CPPC, Yunnan Province) and Fan Mian (former Director, Honghe Institute of Cultural Relics) for assistance with establishing and managing the project. We thank You Pingping for research assistance during the duration of the project, and Zhang Tao $(\mathrm{Hu}$ nan Institute of Cultural Relics and Archaeology) for assistance with fieldwork at Maludong in 2008. VFTB analysis was undertaken by AIRH at the University of Liverpool Geomagnetism Laboratory (UK) with the support of Mimi Hill and Andy Biggin. Finally, we wish to thank anonymous reviewers whose comments improved our work and the editors of Chinese Science Bulletin for their assistance.

1 Zhang X Y, Zheng L, Yang L C, et al. Human fossils and the paleoculture from Mengzi (in Chinese). In: Yunnan Provincial Museum, ed. On Human Origin and Prehistoric Culture of Yunnan. Kunming: Yunnan Renming Press, 1991. 234-246

2 Wu X Z, Poirier F W. Human Evolution in China. New York: Oxford University Press, 1995

3 Curnoe D, Ji X P, Herries A I R, et al. Human remains from the Pleistocene-Holocene transition of Southwest China suggest a complex evolutionary history for East Asians. PLoS One, 2012, 7: e31918

4 Fink D, Hotchkis M, Hua Q, et al. The ANTARES AMS facility at 
ANSTO. In: Nakamura T, Kobayashi K, Matsuzaki H, et al., eds. Proceedings of the Ninth International Conference on Accelerator Mass Spectrometry. Nucl Instrum Methods B, 2004, 223-224: 109-115

5 Hua Q, Jacobsen G E, Zoppi U, et al. Progress in radiocarbon target preparation at the ANTARES AMS Centre. Radiocarbon, 2001, 43: 275-282

6 Cheng H, Edwards R L, Hoffa J, et al. The half-lives of uranium-234 and thorium-230. Chem Geol, 2000, 169: 17-33

7 Hellstrom J C. Rapid and accurate U/Th dating using parallel ioncounting multi-collector ICP-MS. J Anal Atom Spec, 2003, 18: 1346-1351

8 Hellstrom J C. U-Th dating of speleothems with high initial Th-230 using stratigraphical constraint. Quat Geochron, 2006, 1: 289-295

9 Herries A I R. New approaches for integrating palaeomagnetic and mineral magnetic methods to answer archaeological and geological questions on Stone Age sites. In: Fairbairn A, O'Connor S, Marwick B, eds. New Directions in Archaeological Science (Terra Australis 28). Canberra: Australian National University Press, 2009. 235-253

10 Herries A I R, Fisher E. Multi-dimensional modelling of magnetic mineralogy as a proxy for fire use and spatial patterning: Evidence from the Middle Stone Age sea cave site of Pinnacle Point 13B (Western Cape, South Africa). J Hum Evol, 2010, 59: 306-320

11 Walden J, Oldfield F, Smith J. Environmental Magnetism: A Practical Guide. London: Quaternary Research Association Technical Guide, Vol. 6, 1999

12 Brown K S, Marean C W, Herries A I R, et al. Fire as an engineering tool of early modern humans. Science, 2009, 325: 859-862

13 Howells W W. Skull Shapes and the Map. Cambridge, Mass.: Papers of the Peabody Museum of Archaeology and Ethnology, Vol. 79, 1989

14 Martin R. Lehrbuch der Anthropologie. 2nd ed. Jena: Gustav Fisher, 1928

15 Wood B A. Hominid Cranial Remains. Koobi Fora Research Project, Vol. 4. Oxford: Clarendon Press, 1991

16 Alba D M, Moya-Sola S, Madurell M A, et al. Dentognathic remains of Macaca (Primates, Cercopithecidae) from the late early Pleistocene of Terrassa (Catalonia, Spain). J Hum Evol, 2008, 55: 11601163

17 Biggerstaff R H. Metric and taxonomic variations in the dentitions of two Asian Cercopithecoid Species: Macaca mulatta and Macaca speciosa. Am J Phys Anthropol, 1966, 24: 231-238

18 Fooden J. The bear macaque, Macaca arctoides: A systematic review. J Hum Evol, 1990, 19: 607-686

19 Iwamato M. On a skull of a fossil macaque from the Shikimizu lime stone quarry in the Shikoku District, Japan. Primates, 1975, 16: 83-94

20 Tesakov A S, Maschenko Y N. The first reliably identified macaque (Cercopithecidae, Primates) from the Pliocene of Ukraine. Paleon J, 1992, 26: 47-52

21 Bermúdez de Castro J M, Nicolas M E. Posterior dental size reduction in hominids: The Atapuerca evidence. Am J Phys Anthropol, 1995, 96: 335-356

22 Bermúdez de Castro J M, Martinón-Torres M, Gómez-Robles A, et al Comparative analysis of the Gran Dolina-TD6 (Spain) and Tighennif (Algeria) hominin mandibles. Bull mém Soc d'Anthropol Paris, 2007, 19: $149-167$

23 Bermúdez de Castro J M, Pérez-González A, Martinón-Torres M, et al. A new early Pleistocene hominin mandible from Atapuerca-TD6, Spain. J Hum Evol, 2008, 55: 729-735

24 Bermúdez de Castro J M, Martinón-Torres M, Gómez-Robles A, et al. Early Pleistocene human mandible from Sima del Elefante (TE) cave site in Sierra de Atapuerca (Spain): A comparative morphological study. J Hum Evol, 2011, 61: 12-25

25 Brown P, Maeda T. Liang Bua Homo floresiensis mandibles and mandibular teeth: A contribution to the comparative morphology of a new hominin species. J Hum Evol, 2009, 57: 571-596

26 Carbonell E, Bermúdez de Castro J M, Parés J M, et al. The first hominin of Europe. Nature, 2008, 452: 465-469

27 Cuong N L. Two early Hoabinhian crania from Thanh Hoa Province, Vietnam. Z Morph Anthropol, 1986, 77: 11-17
28 Dizon E, Détroit F, Sémah F, et al. Notes on the morphology and age of the Tabon Cave fossil Homo sapiens. Curr Anthropol, 2002, 43: 660-666

29 Hrdlicka A. New data on the teeth of early man and certain fossil European apes. Am J Phys Anthropol, 1924, 7: 109-130

30 Kaifu Y, Aziz F, Baba H. Hominid mandibular remains from Sangiran: 1952-1986. Am J Phys Anthropol, 2005, 128: 497-519

31 Kaifu Y, Zaim Y, Baba H, et al. New reconstruction and morphological description of a Homo erectus cranium: Skull IX (Tjg-1993.05) from Sangiran, Central Java. J Hum Evol, 2011, 61: 270-294

32 Liu W, Jin C Z, Zhang Y Q, et al. Human remains from Zhirendong, South China, and modern human emergence in East Asia. Proc Natl Acad Sci USA, 2010, 107: 19201-19206

33 Mallegni F, Fabbri P F. The human skeletal remains from the Upper Palaeolithic burials found in Romito cave (Papasidero, Cosenza, Italy). Bulle Mém Soc d'anthropol Paris, 1995, 7: 99-137

34 Martinón-Torres M, Bermúdez de Castro J M, Gómez-Robles A, et al Dental remains from Dmanisi (Republic of Georgia): Morphological analysis and comparative study. J Hum Evol, 2008, 55: 249-273

35 Martinón-Torres M, Bermúdez de Castro J, Gómez-Robles A, et al. Morphological description and comparison of the dental remains from Atapuerca-Sima de los Huesos site (Spain). J Hum Evol, 2012, 62: 7-58

36 Matsumura H, Pookajorn S. A morphometric analysis of the late Pleistocene human skeleton from the Moh Khiew Cave in Thailand. J Comp Hum Biol, 2005, 56: 93-118

37 Matsumura H, Zuraina M. Metric Analyses of an early Holocene human skeleton from Gua Gunung Runtuh, Malaysia. Am J Phys Anthropol, 1999, 109: 327-340

38 Matsumura H, Yoneda M, Dodo Y, et al. Terminal Pleistocene human skeleton from Hang Cho Cave, northern Vietnam: Implications for the biological affinities of Hoabinhian people. Anthropol Sci, 2008, 116: 201-217

39 McBurney C B M, Trevor J C, Wells L H. The Haua Fteah fossil jaw. J Roy Anthropol Inst (Great Britain \& Ireland), 1953, 8: 71-85

40 McCown T D, Keith A. The Stone Age of Mount Carmel: The Fossil Human Remains from the Levalloiso-Mousterian. Oxford: Oxford at the Clarendon Press, 1939

41 Shang $\mathrm{H}$, Tong $\mathrm{H} \mathrm{W}$, Zhang S Q, et al. An early modern human from Tianyuan Cave, Zhoukoudian, China. Proc Natl Acad Sci USA, 2007, 104: 6573-6578

42 Sollas W J. The Chancelade skull. J Roy Anthropol Inst (Great Britain \& Ireland), 1927, 57: 89-122

43 Tobias P V. Human skeletal remains from the Cave of Hearths, Makapansgat, Northern Transvaal. Am J Phys Anthropol, 1971, 34: 335-368

44 Trinkaus E, Marks A E, Brugal J P, et al. Later Middle Pleistocene human remains from the Almonda Karstic system, Torres Novas, Portugal. J Hum Evol, 2003, 45: 219-226

45 Tyler D E. Three new Homo erectus mandibles from Java. J Hum Evol, 2001, 16: 103-115

46 Vandermeesch B. Les Hommes Fossiles de Qafzeh (Israël) (In French). Paris: Éditions du Centre National de la Recherche Scientifique, 1981

47 Verna C, Dujardin V, Trinkaus E. The early Aurignacian human remains from La Quina-Aval (France). J Hum Evol, 2012, 61: 605-617

48 Weidenreich F. The dentition of Sinanthropus pekinensis: A comparative odontography of the hominids. Palaeontol Sin New Ser D, 1937, 1: $1-180$

49 Liu W, Wu X Z, Pei S W, et al. Huanglong Cave: A late Pleistocene human fossil site in Hubei Province, China. Quat Inter, 2010, 211: 29-41

50 Herries A I R, Reed K, Kuykendall K L, et al. Speleology and magnetobiostratigraphic chronology of the Buffalo Cave fossil bearing palaeodeposits, Makapansgat, South Africa. Quat Res, 2006, 66: 233245

51 Dearing J. Magnetic susceptibility. In: Walden J, Oldfield F, Smith J, eds. Environmental Magnetism: A Practical Guide. London: Quaternary Research Association Technical Guide, Vol. 6, 1999. 35-62

52 Hemming S R. Heinrich events: Massive late Pleistocene detritus 
layers of the North Atlantic and their global climate imprint. Rev Geophys, 2004, 42: 1-43

53 Southon J, Noronha A L, Cheng H, et al. A high-resolution record of atmospheric ${ }^{14} \mathrm{C}$ based on Hulu Cave speleothem H82. Quat Sci Rev, 2012, 33: 32-41

54 Fooden F. Ecosegregation of the macaque species. Primates, 1982, 23: 574-579

55 Timmins R J, Duckworth J W. Distribution of habitat of Assamese Macaque Macaca assamensis in Lao PDR, including its use of lowaltitude karsts. Prim Conserv, 2011, 26: 1-12

56 Nisbett R A, Ciochon R L. Primates in northern Viet Nam: A review of the ecology and conservation status of extant species with notes on Pleistocene localities. Int J Primatol, 1993, 14: 765-795

57 Li H J, Wu X J, Li S H, et al. Late Pleistocene human skull from Jingchuan, Gansu Province. Chin Sci Bull, 2010, 55: 1047-1052

58 Trinkaus E. Early modern humans. Annu Rev Anthropol 2005, 34 : 207-230

59 Etler D. The fossil evidence for human evolution in Asia. Ann Rev Anthropol, 1996, 25: 275-301

60 Zhang X Y, Cao F, Yue Q. A preliminary study of the human skull fossil of Yaoguan, Shidian (in Chinese). In: Zhang X Y, Gen D M, eds. Baoshan Prehistory Culture. Kunming: Yunnan Science \& Technology Press, 1993. 80-89

61 Shackelford L, Demeter F. The place of Tam Hang in Southeast Asian human evolution. Comptes Rendus Palevol, 2012, 11: 97-115

62 Kong Q P, Sun C, Wang H W, et al. Large-scale mtDNA screening reveals a surprising matrilineal complexity in East Asia and its implications to the peopling of the region. Mol Biol Evol, 2011, 28: 513-522

63 Jinam T J, Hong L H, Phipps M E, et al. Evolutionary history of continental Southeast Asians: "Early Train" hypothesis based on genetic analysis of mitochondrial and autosomal DNA data. Mol Biol Evol, 2012, 29: 3513-3527

64 Reich D, Green R E, Kircher M, et al. Genetic history of an archaic hominin group from Denisova Cave in Siberia. Nature, 2010, 468: 1053-1060

65 Reich D, Patterson N, Kircher M, et al. Denisova admixture and the first modern human dispersals into Southeast Asia and Oceania. Am J Hum Gen, 2011, 89: 516-528

66 Zhang C, Hsiao-Chun H. Later hunter-gatherers in southern China, 18000-3000 BC. Antiquity, 2012, 86: 11-29

Open Access This article is distributed under the terms of the Creative Commons Attribution License which permits any use, distribution, and reproduction in any medium, provided the original author(s) and source are credited. 